\title{
Can Large-Scale Climatic Models Be Linked with Multiscale Ecological Studies?*
}

\section{TERRY L. ROOT}

School of Natural Resources and Environment

University of Michigan

Ann Arbor, MI 48109, U.S.A.

\section{STEPHEN H. SCHNEIDER}

National Center for Atmospheric Research**

Boulder, CO 80307, U.S.A.

and

Department of Biological Sciences and

Institute for International Studies

Stanford University

Stanford, CA 94305, U.S.A.

\begin{abstract}
On a global scale, climatic changes driven by bu. man activities are typically projected to increase from $1^{\circ} \mathrm{C}$ to $5^{\circ} \mathrm{C}$ per 100 years, a rate of cbange that is an order of magnitude greater than that typically experienced naturally. Sucb a potentially dramatic change in climate could easily cause dramatic biological responses, including extinction. Species show a wide range of responses to climate, and consequently the response of different species of plants and animals to climatic cbange will be quite variable. This implies a likelibood for a disassembling of natural communities and for transient, nonequilibrium restructuring of babitats as climatic change unfolds. Validated models that belp fore. cast these events are needed to aid scientists in better understanding the ecological ramifications of global climatic change. Also, and perbaps more important for conservation biology, such validated models can help provide probabilities for the occurrence of these events, which will allow policy makers to make better, informed decisions. Typically, the study plots of most ecological field work are tennis-courtsized, while the smallest resolved scales in global climatic models are about $500 \times 500 \mathrm{~km}$. Computer limitations preclude significant reduction in scales of climatic models.
\end{abstract}

\footnotetext{
- Portions of this paper are adapted from Root (1993) and Schnetder (1993a).

- The National Center for Atmosphertc Research ts sponsored by the National Science Foundation.

Any opinions, findings, conclusions or recommendations expressed in this article are those of the authors and do not necessarily reflect the vieus of the National Science Foundation.

Paper submitted September 6, 1991; revised manuscript accepted July 7, 1992.
}

Pueden los modelos climáticos a gran escala conectarse con estudios ecológicos a multiples escalas?

Resumen: A una escala global, los cambios climáticos generados por activadades bumanas estan tipicamente proyectados para producir un incremento del 1 a $5^{\circ} \mathrm{C}$ en 100 años, esta taza de cambio es de un orden de magnitud mayor que la experimentada naturalmente Este dramático cambio potencial puede fácilmente producir dramáticas respuestas biologicas (incluyendo extincion). Las especies que muestran un amplio rango de respuestas al clima y consecuentemente la respuesta de diferentes espectes de plantas y animales a cambios climáticos va a ser significativamente variable. Esto implica la posibilidad de un desmembramiento de comunidades naturales y una reestructuración desequilibrada y transitorla de bábitats a medida que los cambios climáticos ocurran. Modelos válidos que ayu. den a predecir estos eventos son necesarios para ayudar a los cientificos a una mejor comprension de las ramificaciones ecologicas de los cambios climáticos globales. Adicionalmente, y posiblemente más importante para la conservación biologica, es la validación de estos modelos que puede ayudar a proveer probabilidades de ocurrencia de estos eventos, los cuales pueden ayudar a los encargados de la toma de decisiones a realizar mejores decistones con mas información. Típicamente, el trabajo de campo de la mayorlu de los estudios ecológicos son del tamaño de canchas de tents, mientras que la menor escala en modelos climáticos globales es de apraximádamente $500 \times 500 \mathrm{~km}$. Obviamenteexiste una gran diferencia en escala Limitaciones compu- 
Consequently, more multi-species ecological studies are needed over broad geographic and long temporal scales. We provide an example of lange-scale ecological response studies, namely the case of wintering North American birds. We also provide an example of attempts to translate results of large-scale climatic models (at a $500 \times 500 \mathrm{~km}$ scale) to a mesoscale $(50 \times 50 \mathrm{~km})$. Participation of climatologists with ecologists at early stages in research planning can belp bridge the scale mismatch between climatic and ecological measurement, and provide more reliable estimates of community responses to century-long time-evolving patterns of climatic change. We are convinced tbat many more such interdisciplinary research attempts are urgently needed if the scientific community is to produce information useful to the development of conservation strategies. Sucb strategies migbt belp to mitigate potential negative consequences of global climatic changes before they manifest themselves irreversibly in nature. tacionales impiden significativamente la reducción en las escalas de modelos climáticos. Consecuentemente, más estudios ecologicos multiespecíficos, son necesarios sobre una amplia escala geográfica y temporal Nosotros proveemos un ejemplo de un estudio de respuestas ecologicas a gran escala, como el caso de los pájaros del invierno en Norte América. Nosotros también proveemos un ejemplo que intenta trasladar los resultados de un modelo climático a gran escala $(500 \times 500 \mathrm{~km})$ a un modelo de escala media (ie, $50 \times 50$ km). La participación de climatologos y ecologos en los estadíos tempranos del planeamiento de una investigación puede ayudar a salvar las diferencias de escalas entre las medidas climáticas y las ecológicas y proveer estimaciones más confiables de las respuestas de la comunidad a cambios climáticos de siglos de duración y que evolucionen con el tiempo. Nosotros estamos convencidos que mucho más de estos intentos de investigación interdisciplinaria son urgentemente necesarios si la comunidad cientifica desea pro. ducir información que sea útil para el desarrollo de estrategias de conservación. Este tipo de estrategias pueden ayudar a mitigar las consecuenctas negativas potenciales de los cambios climáticos globales antes de que estos se manifiesten imeversiblente en la naturaleza.

be significant enough to precipitate measurable distribution changes in some species and probably facilitate some extinctions (see McDonald \& Brown 1992). Forecasts of possible biological consequences for the entire range of projected rise in global temperature will be helpful in providing the guidance needed to avert or at least to help plan for disruptions of communities and ecosystems.

The possible biological changes would not only be due to increased temperature per se, but-probably more important - to the rate of the increase. The rapid rate of change would force transient variations in both mean and extreme climatic statistics. Any alterations to the character of extreme weather events could be quite biologically significant (such as massive die offs of Eastern Bluebird, House Wren, Eastern Phoebe, and Hermit Thrush during severe cold snaps [James 1962]). Also, the anticipated changes in global climate are expected to occur at a rate most biologists acknowledge as simply too fast for evolutionary processes, such as natural selection, to keep pace (but see Lynch and Lande [1993] for an alternative view). Such constraints on species' abilities to adapt to their rapidly changing habitats could substantially enhance the probability of extinction of numerous species. Indeed, the importance of the difference between evolutionary and ecological time scales was noted by Davis (1990):

The fossil record shows that most forest trees were able to disperse rapidly enough to keep up with most of the climatic changes that took place in recent millennia. biological consequences of even the low scenario could 
These changes were much more gradual than the climatic changes projected for the future. Even so, there were occasional periods of disequilibrium between plant distributions or abundances, soils, and climate that lasted a century or more. The most rapid dispersal rates known from the fossil record, however, are an order of magnitude too slow to keep up with the temperature rise expected in the coming century.

Quite simply, tree species generally take hundreds or even thousands of years for substantial dispersal, while significant temperature rise is forecast to be an order of magnitude faster than that. Also, land use by humans has fragmented the natural environment in such a way that dispersal of individuals and expansion of ranges will be limited without substantial human intervention (Wilcove et al. 1986; Arnold 1988; Main 1988). Hence, the biological consequences of the impending warming event could easily be significantly more severe than any comparable event in prehistoric times. Many more species could go extinct, and the reshaping of ranges could be more extreme.

Such biological disruption could greatly influence the functioning of ecosystems. Indeed, a tearing apart of species' communities quite possibly would occur, with the ranges of some species moving farther and faster than others. Each species has its own unique ecological and physiological needs (Whittaker 1970:158) and, as a result, different responses to environmental changes will be exhibited by each species (Strain 1987; Cohn 1989). Consequently, species-specific studies are needed to help us understand the ecology, behavior, evolution, and physiology of as many species as possible, particularly those that could be viewed as keystones in various communities. Studies are also needed on a local scale to help us understand interactions of species within communities, and on a regional scale to allow investigation of entire ecosystems. Even though we do not know what the exact increase in the global temperature will be or how regional climates will change, various models exist that can help us predict possible changes (e.g., IPCC 1990, 1992). These models, coupled with our knowledge of species, communities, and ecosystems, will allow us to make more reliable projections of the potential biological consequences of those changes.

The mismatch of scales between the models and the biological studies, however, detracts significantly from our ability to forecast reliably the effect of global climatic change on living organisms (e.g., Levin 1992). For instance, most ecological studies are carried out in areas roughly the size of a tennis court (Kareiva \& Andersen 1988), while the resolution of most climate models is approximately the size of the state of Colorado. A handful of studies do exist that attempt to bridge this gulf between scales (see Terborgh 1971; Gates 1985; Root 1988a, 1988b; Brown \& Maurer 1989), but certainly more needs to be done to help us understand the complexities of how living organisms will react to climatic change. The purpose of this paper is to discuss approaches that attempt to reduce the mismatch. We also provide examples of successful "bridging" studies that examine and suggest avenues for future work. These studies provide examples of how such work can be used as a foundation upon which the small-scale biological studies and large-scale climatic studies can be coupled to clarify further the possible biological consequences of global climatic change.

\section{Global Warming Scenarios Relevant to Ecosystem Studies}

Scientists estimating future climatic changes have focused on large-scale models of the climate-general circulation models (GCMs) -that attempt to represent mathematically the complex physical and chemical in. teractions among the atmosphere, oceans, ice, biota, and land. As these models have evolved, more and more information has become available and morecomprehensive simulations have been performed. Nevextheless, the complexities of the real climate system still vastly exceed the comprehensiveness of today's GCMs and the capabilities of today's computers (see IPCC $[1990,1992]$ for a state-of-the-art review and Schneider [1991] for a review of the IPCC process). Simulating one year of weather in 30-minute "time steps" with the crude resolution of $4.5^{\circ}$ latitude by $7.5^{\circ}$ longitude and ten vertical layers (nearly 20,000 "grid boxes" around the globe) takes approximately 10 hours of Cray Y-MP time. Such a grid cannot resolve the Sierras and Rocky Mountains as separate mountain chains. Refining the resolution to $50 \times 50 \mathrm{~km}$ grid squares would so dramatically increase the number of computations that it would take on the order of one year of currentgeneration computer time to calculate one year's weather statistics. Obviously, many important imponderables in the models are unlikely to be resolved before significant climatic changes are felt, and certainly not before we are committed to potentially significant long-term environmental and societal effects. Therefore, we will not have the luxury of solving every significant detail before having to apply the existing models to help avert potentially serious crises involving the degradation of ecosystems. Using the existing models, however, to help guide such preventative applications should buy some time, thereby allowing us the opportunity to pursue disciplinary and interdisciplinary research on the basic interactions and finer details.

What is most needed to evaluate potential biological effects of temperature change is a regional projection of climatic changes that can be applied to ecosystems. 
Analyses of large, prehistoric climatic changes (see Berger et al. 1984; Barron \& Hecht 1985; Budyko et al. 1987; Schneider 1987; COHMAP 1988) and historical weather analogues (Pittock \& Salinger 1982; Jager \& Kellogg 1983; Lough et al. 1983) provide some insights to such changes. These methods, however, are also based on climatic cause-and-effect processes that probably are different from future greenhouse-gas radiative effects (Schneider 1984; Mearns et al. 1990a; Crowley 1993).

GCM forecasts at the regional scale are known to be more uncertain than those at larger scales (see IPCC 1992). Regional temperature changes can be much more extreme than the global average, with some regions even showing a negative change (see Schlesinger \& Mitchell 1987; IPCC 1990). For example, surfacetemperature increases projected for the higher northern latitudes are up to several times larger than the projected global average response, at least in equilibrium. This could imply sea level changes from changes in ocean volume or snow balance, but estimates (typically $0.5 \mathrm{~m} \pm 0.5 \mathrm{~m}$ rise in sea level by 2100 ) are controversial (see Schneider 1992a).

Even more uncertain than regional details, but perhaps more important to long-term ecosystem responses, are estimates of climatic variability during the transition to a new equilibrium, particularly at the original scale. These include such events as frequency and magnitude of severe storms, enhanced heat waves, temperature extremes, or reduced frost probabilities (Mearns et al. 1984, 1990b; Parry \& Carter 1985; Wigley 1985; Rind et al. 1989). For example, the physical principle which notes that evaporation increases exponentially with surface-water temperature implies that hurricane intensities and length of the hurricane season could increase with warming of the oceans (Emanuel 1987). This obviously would have significant impact on the ecosystems, both terrestrial and marine, in the paths of such hurricanes (Doyle 1981; O'Brien et al. 1992).

GCMs are capable of providing estimates of hourly, daily, monthly, or interannual variability for various climatic variables. Climatic variables of central importance to ecologists (for example, the probability of three weeks of temperatures over $30^{\circ} \mathrm{C}$ with relative humidity below $25 \%$ is a major correlate with forest fire likelihood [Torn \& Fried 1992]), however, are rarely considered by climate modelers. Thus, ecologists and climatologists must discuss the need for nontraditional measures of climatic variability to facilitate the type of interdisciplinary research needed. Such collaborations are in their infancy, and the vast majority are based on so-called "equilibrium" results of climatic models in which $\mathrm{CO}_{2}$ is doubled and held fixed over time. Because the actual greenhouse gas increases are time evolving and exponentially growing, these studies will, of course, have to be expanded to include realistic transient cases before they can be of maximum value to ecologists or other impact assessors.

\section{Narrowing the Mismatch between Ecological Studies and Climatic Model Scales}

As noted earlier, even the highest-resolution threedimensional GCMs will not have a grid with nodes much less than $100 \mathrm{~km}$ apart within the foreseeable future; individual clouds and most ecological research (to say nothing of cloud microphysics or microclimatic or microphysiological research), for example, occur on scales far smaller than that. GCMs will not, therefore, be able to resolve weather affecting most local biological communities or the importance of local and mesoscale effects of hills, coastlines, lakes, vegetation boundaries, and heterogeneous soil. For regions that have relatively uniform surface characteristics, however, such as a 1000-km savannah or a tropical forest with little elevation change, GCM grid-scale parametric representations of surface albedo, soil type, and evapotranspiration could be used to estimate local changes. Alterations in climate predicted within one grid square would likely apply fairly uniformly across such homogeneous areas, but steep topography or lakes smaller than GCM grids, both of which can mediate real climate, are not resolved in the models. Therefore, the GCM predictions are only infrequently accurate at a regional or smaller scale.

Large-scale observed climatic anomalies can be mapped to local variations. For instance, Gates (1985) analyzed the local climatic variability for the state of Oregon using a technique known as empirical orthogonal functions (Fig. 1). A GCM run that produces altered temperatures that are resolved on the western slope of the Cascades could be applied to the climatic-anomaly map of Oregon to determine the climatic effects on lo$\mathrm{cal}$ areas of the eastern slopes of the Cascades (which are not resolved in the model). Such a map, constructed from variations of climate observed over several years, may seem an ideal way to translate the GCM grid-scale averaged data to the local or mesoscale. Because empirical data have been used, however, such a relation would be valid only where the causes of recent climatic variations or oscillations carry forward and include the effect of climatic changes forced by trace gases. The north-south Cascade Mountains translate a simple change in the frequency or intensity of westerly winds into a characteristic climatic signature of either cooler and wetter on the west slope and warmer and drier on the east or vice versa. Thus, the signature of climatic change from increases in trace gases may not be the same as from past vacillations, many of which could have been internal oscillations within the climatic system, not the result of external climatic forcing (any process that can force the climate to change is known as 

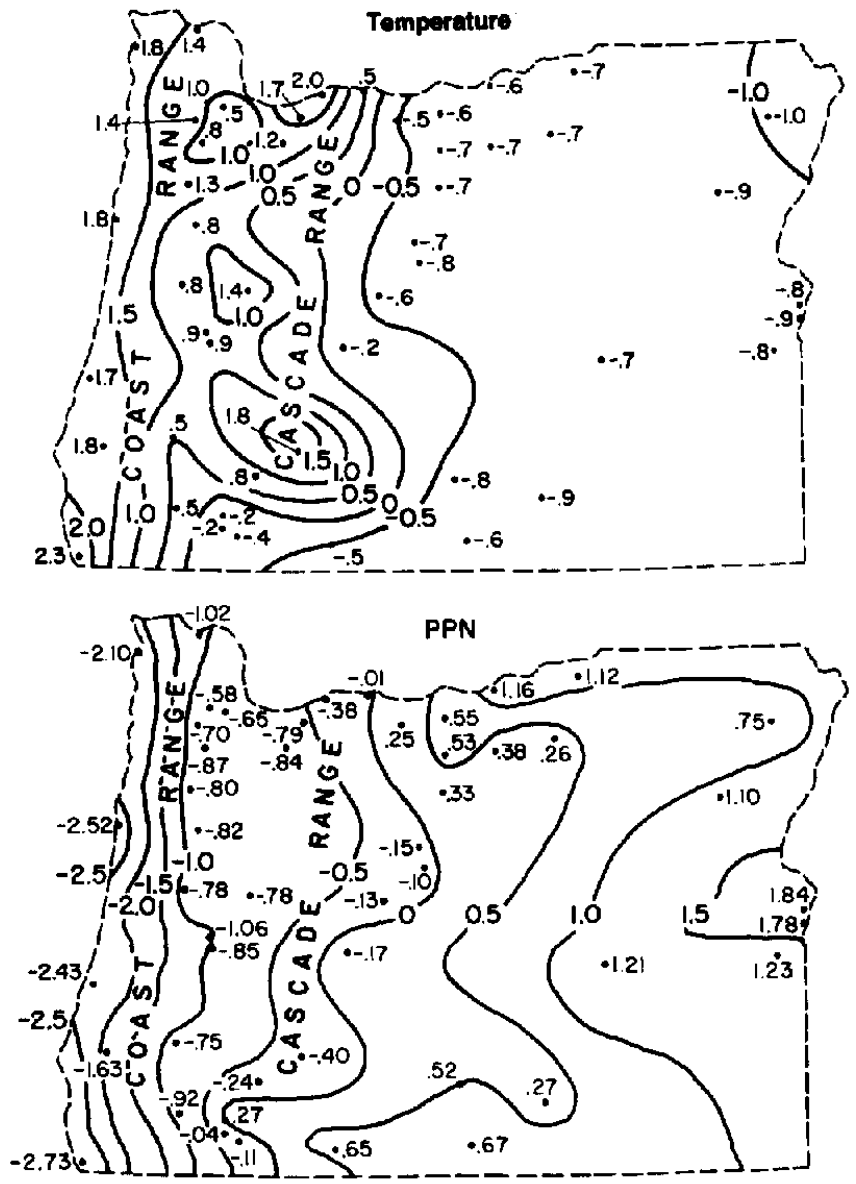

Figure 1. The distribution of the relationship between large-scale (area-averaged) and local variations of the monthly mean surface air temperature (above) and precipitation. (below), as given by the first empirical ortbogonal function determined from 30 years of observational monthly means at 49 stations in Oregon in comparison with the statewide average. Source: Gates 1985.

"climatic forcing") such as changes in trace gases. For example, an increase in temperature on the western slopes of the Cascades will not necessarily (despite Fig. 1) imply a decrease in temperature on the eastern slopes if the western-slope temperature rise were forced by greenhouse gas heating; however, eastern-slope cooling might well hold if the western-slope warming were a result of weakened westerlies. Thus, other translations of scale must be considered in mapping large-scale global change projections to smaller scales that account for the causes of the large-scale changes.

One might embed a high-resolution mesoscale model within a few grid squares of a GCM, using as boundary conditions for the mesoscale model the wind, temperature, and so forth, predicted by the GCM at the squares' boundaries (see Dickinson et al. 1989). A mesoscale model, with grid-square scale typically $50 \times 50 \mathrm{~km}$, could then account for regional topography, soil type, and vegetation cover, and could map GCM forecasts to this scale of regional topography. Figure 2 is an example for the western United States. For such a method to have any reasonable hope of success, however, the GCM must produce reasonably accurate grid-scale climatic statistics for the special limited grid area. To return to the Oregon case in Figure 1, if the climatic average of the GCM's winds in the unperturbed case (the control case) has the wrong westerly component, the local climatic change will probably be misrepresented in a region where topography amplifies any such error in the wind direction. A likely prerequisite for that kind of cross-scale mapping, therefore, is a sufficiently accurate control climate for the important variables. Only then does it make sense to take the next step of imposing a scenario of trace-gas increase on the GCM to estimate how the climate might change at regional and local scales. Although this technique has shown considerable promise for wintertime climatic situations in middle latitudes, it has not yet been determined how embedding would work in the summer or in the tropics, where thunderstorms (smaller in scale than even the mesoscale grid boxes) dominate precipitating systems.

\section{Unpredictability of Time-Evolving, Transient Climates in Regional Areas}

Neither the IPCC $(1990,1992)$ nor other assessments (for example, National Academy of Sciences 1987; Schneider 1990) indicate that a strong consensus exists among scientists regarding time-evolving, regionallyspecific climatic changes. For example, the world is undergoing a steady increase in greenhouse-gas forcing, gases distributed fairly uniformly around the globe. Superficially, one might expect a uniform global response, but this is far from likely. The centers of continents have relatively low heat-retaining capacity, and thus their new equilibrium climate would be reached more rapidly than that at the centers of oceans, which are thermally more stable. Tropical oceans, however, have a thin surface layer (on the order of $50 \mathrm{~m}$ ) of well-mixed waters. The temperature of that mixed layer changes substantially over 10 -year time scales, which is much slower than the response time of the middle of continents, but again much faster than the rate at which the surface temperatures change at high-latitude oceans, where waters can mix down to the floor of the ocean. Therefore, during the transient phase of climatic change, middle of continents, middle of oceans, tropical oceans, and high-latitude oceans all are approaching their new equilibrium temperatures at different rates (Schneider \& Thompson 1981). This means the temperature differences from land-to-sea and equator-to-pole will change over time, which suggests that regional climatic anomalies associated with global warming will not 
(a)

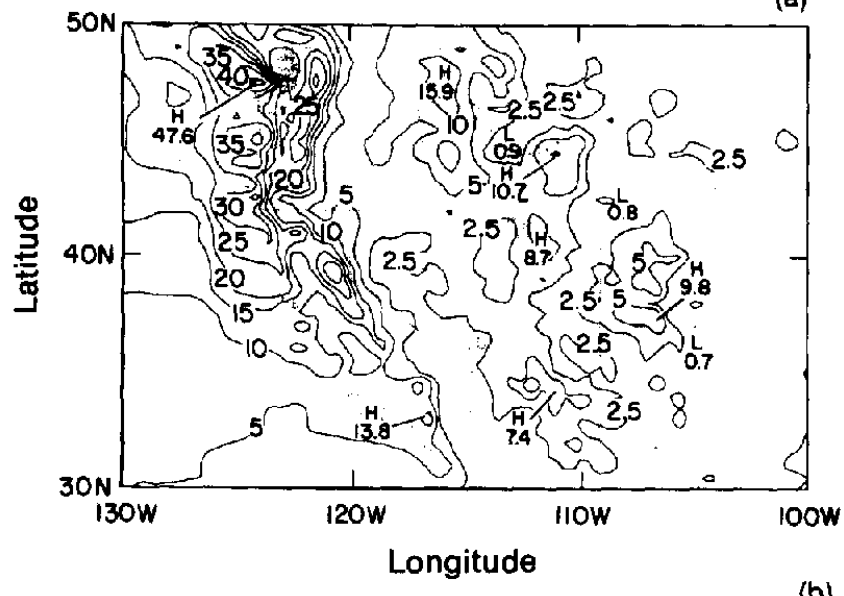

(b)

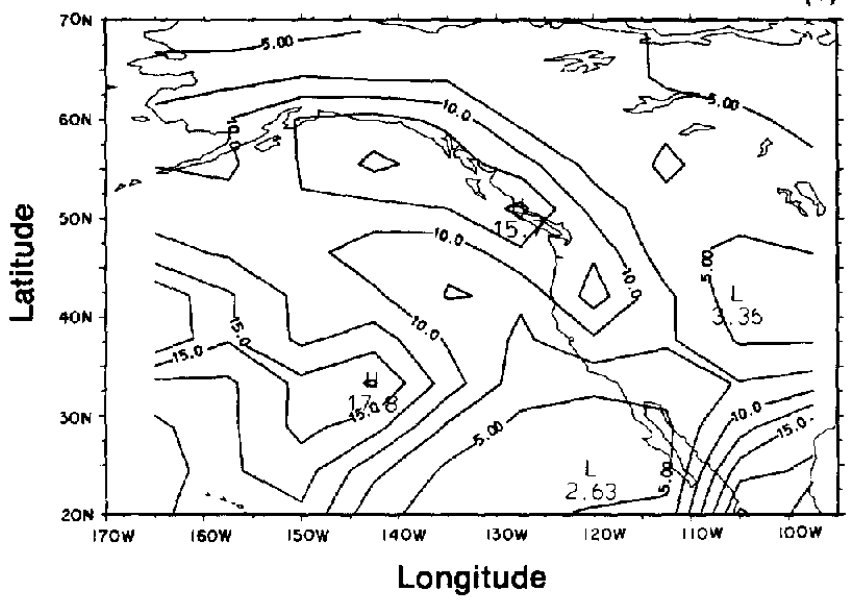

(c)

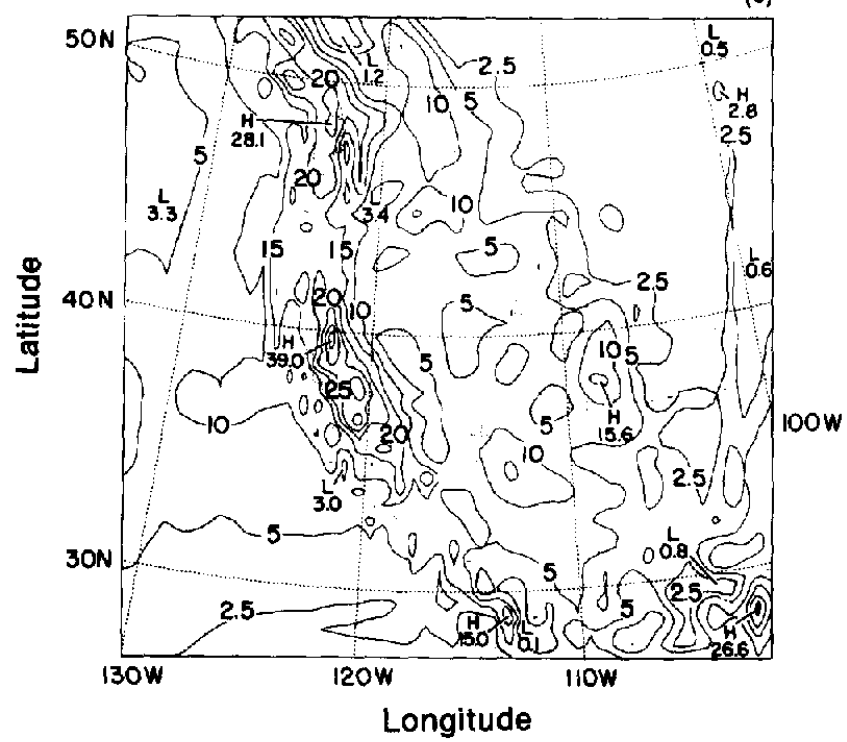

Figure 2. Average January total precipitation (centimeters): (a) observations; (b) R15 general circulation model $\left(4.5^{\circ}\right.$ latitude by $7.5^{\circ}$ longitude resolution); (c) mesoscale model driven by output of R15 model Source: Giorgi 1990. necessarily increase uniformly over time, but could have a transient character very different from the longterm equilibrium character (Stouffer et al. 1989; Washington \& Meehl 1989).

The lack of credible predictability through time on a regional scale has implications for evaluating the adaptability of various ecosystems. The anomalous weather at one time, for example, may be extreme enough to dramatically restrict genetic variability by killing off maladapted individuals; then when the weather rapidly changes to the other extreme, the previously adapted individuals are now themselves maladapted (Watt 1992). The result could easily be extinction. A rapidly changing regional climate would be particularly stressful for natural ecosystems, because the vast majority of habitats cannot be artificially protected from transient effects (for example, by seeding or transplanting hardier species into the area, or by providing needed soil nutrients by applying fertilizers). Moreover, the less predictable regional climatic changes are, the more difficult it will be to maintain sound conservation practices. Also the more rapidly the climate is forced to change by, say, growing greenhouse-gas emissions, the less predictable regional changes will become (Thompson \& Schneider 1982).

\section{Forecasting Large-Scale Vegetational Responses to Rapid Climatic Change}

Despite the difficulties in providing precise regional projections of climatic changes, plausible scenarios (such as those in IPCC 1990) can be postulated and used to drive ecosystem-response models (see Pastor \& Post 1988). But before the consequences of any global warming scenario on ecosystems can be accurately forecast, a rudimentary understanding is needed about the influence climatic change will have on the various representative biological components. For example, essential characteristics of ecosystems are shaped by vegetation (Graetz et al. 1988), and many studies have shown that climate strongly affects both the distribution of plants and the composition of vegetational communities (see Gates 1980; Woodward 1987:174 and references therein; COHMAP 1988). Even small changes in ambient temperature can cause dramatic effects owing to changes in the physiological demands of the plants. Lower energy demands due to warmer temperatures could easily change the delicate dominance structure that is assumed to be maintained by competition (Strain 1987). Moreover, species disperse at different rates (Cohn 1989), which will result in dramatic alterations of the species composition of all biological communities.

Estimates of transient forest response have been made using so-called "gap" models, first developed by Botkin 
et al. (1972) and then modified, expanded, and applied by many others (such as Pastor \& Post 1988; Bonan et al. 1990; Botkin \& Nisbet 1992). One such latergeneration model (Martin 1990) was used to predict the vegetation composition for 400 years at a Minnesota site, assuming a "normal" climate. Then, after 400 years, a scenario of a $3^{\circ} \mathrm{C}$ per century watming trend was imposed, and the vegetational response was quite significant: the forest disappeared (Martin 1990). The simulated disappearance, Martin notes, depends on internal model assumptions, such as air humidity and biophysical parameterization of leaf temperatures. Therefore, we should not take any one scenario or response projection literally. Martin's results should be taken seriously, however, in as much as they indicate that major shifts in forest species abundances could certainly occur with a few degrees warming and that these shifts would take from decades to centuries to unfold-or to repair.

A species-specific example has been provided by Davis and Zabinski (1992) for the sugar maple. Significant shifts in its range are projected when equilibrium $\mathrm{CO}_{2}$ doubling is assumed (Fig. 3). The extent of the predicted distributional shift is less extreme with the climatic model scenario of the Goddard Institute for

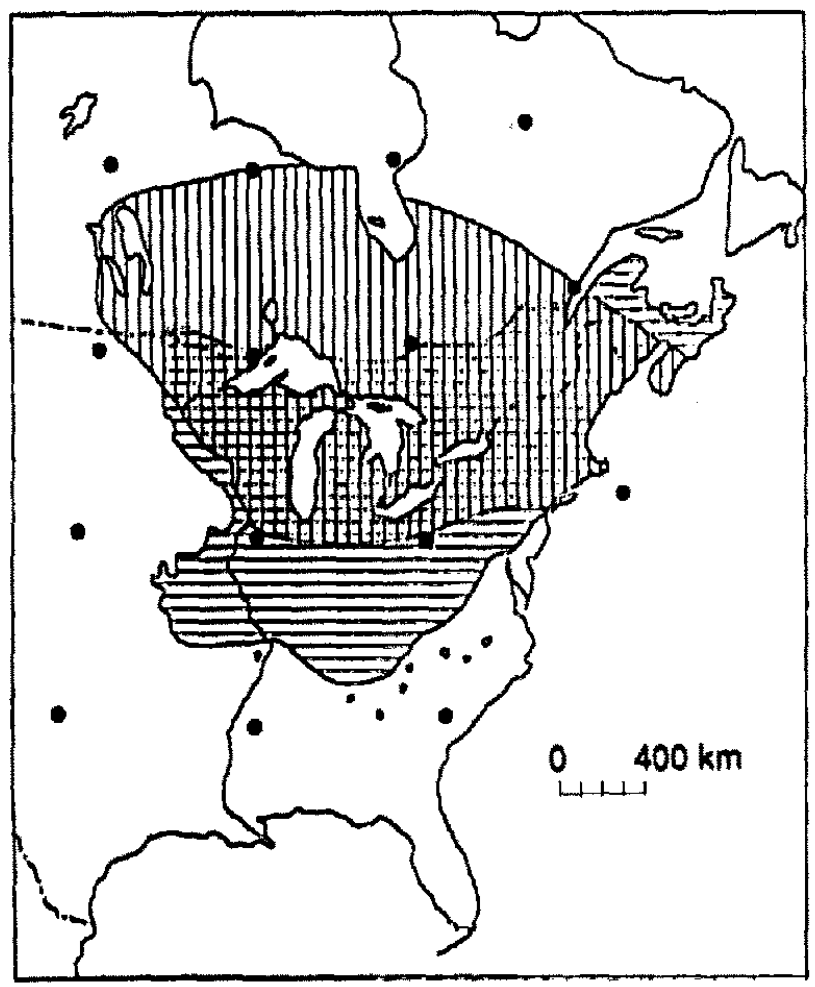

A
Space Studies (Fig. 3A) than with the model scenario of the Geophysical Fluid Dynamics Laboratory (Fig. 3B). In both cases, however, sugar maple not only expands farther north, but massive local die-outs could occur to the south (Davis \& Zabinski 1992). Consequently, even though the details of the equilibrium ranges are not the same, both models indicate significant range changes, which in turn will most certainly cause the structure of both northern and southern communities to change dramatically. And, as stated earlier, both the climatic change scenarios and the ecological response model apply to equilibrium conditions, whereas actual changes will be transient in character in both climatic and ecological systems.

\section{The Importance of Triangle Linkages between Plants, Animals, and Climate on a Large Scale}

The anticipated changes in the ranges of plants will likely have dramatic effects on animals, both on the large biogeographic scale and on the local regional scale. The ranges of many animals have been found to be strongly linked to vegetation. For example, Red-

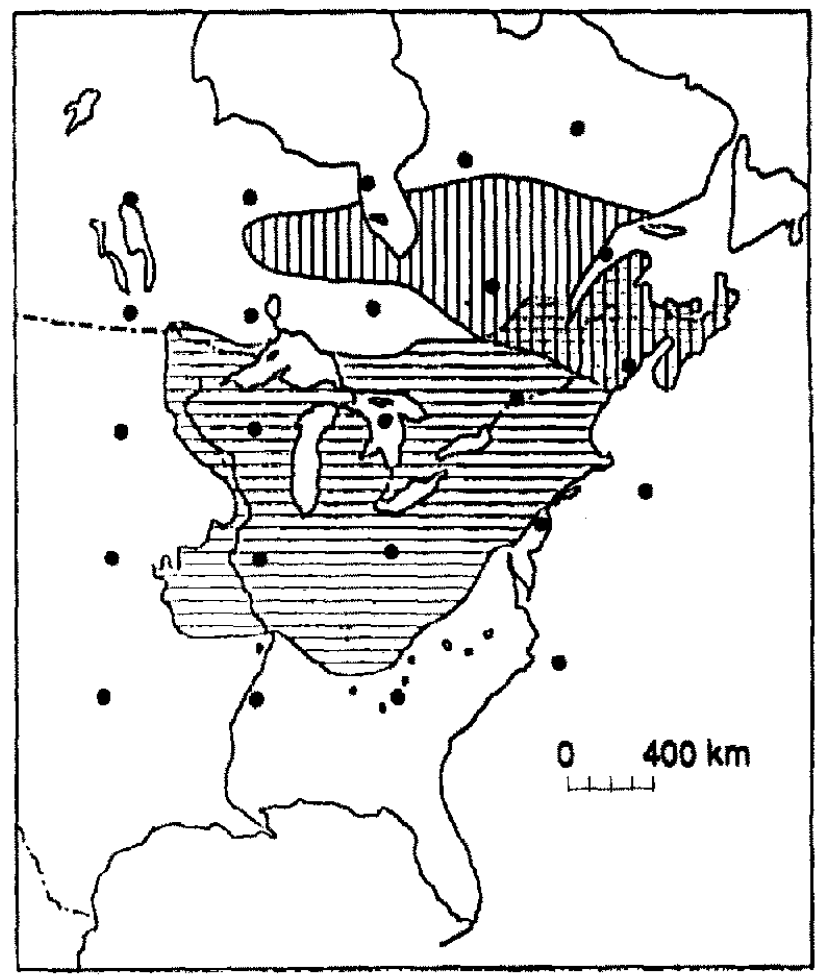

$\mathbf{B}$

Figure 3. Present geographical range of sugar maple (borizontal lines) and potentially suitable range under doubled $\mathrm{CO}_{2}$ (vertical lines). Cross-batching indicates the region of overlap. A: predictions using climate scenario derived from the general circulation model of the Goddard Institute for Space Studies. B: predictions using climate scenario derived from the model of the Goddard Fluid Dynamics Laboratory. Gridpoints (dots) are sites of climatic data output for each model. Source: Davis \& Zabinski 1992. 
Cockaded Woodpeckers are endemic to mature pine and pine-oak forests (Mengel \& Jackson 1977), and the winter range of Sprague's Pipit is coincident with $A \boldsymbol{n}$ dropogon grass (Root 1988c). Consequently, the ranges of various animals that are reliant on vegetation will change as the ranges of plants shift, assuming, of course, that some other factor is not limiting them. If the climate changes more rapidly than the dispersal rate of the plants, resulting in extensive die-offs in the South before individuals can disperse and become established in the North, then the ranges of animals relying on these plants could become compressed. Indeed, in some cases extinction could occur both to the animals and the plants. For instance, the Red-Cockaded Woodpecker needs mature living trees for nesting sites (Jackson 1974). If the rising temperature causes a large majority of mature trees to die before the newly established dispensing individuals reach maturity, then this rare woodpecker could easily go extinct.

Many species of animals have ranges that are not di. rectly limited by vegetation, but instead are restricted by temperature. This is true for most ectotherms (insects and amphibians) as well as some endotherms, such as the Eastern Phoebe, which winters in areas warmer than $4^{\circ} \mathrm{C}$ (Fig. 4; Root 1988a). As the globe warms, those species directly limited by temperature will be able to expand northward as rapidly as their dispersal mechanisms will allow, again assuming other factors are not limiting. The animals limited by vegetation will be able to expand their ranges only as rapidly as the vegetation changes. Consequently, the potential for significant disruption among communities is quite high. For instance, some animals may no longer be able to coexist because an invading species disrupts the balance between competing species or between predator and prey species. Therefore, to understand the ecological conse-

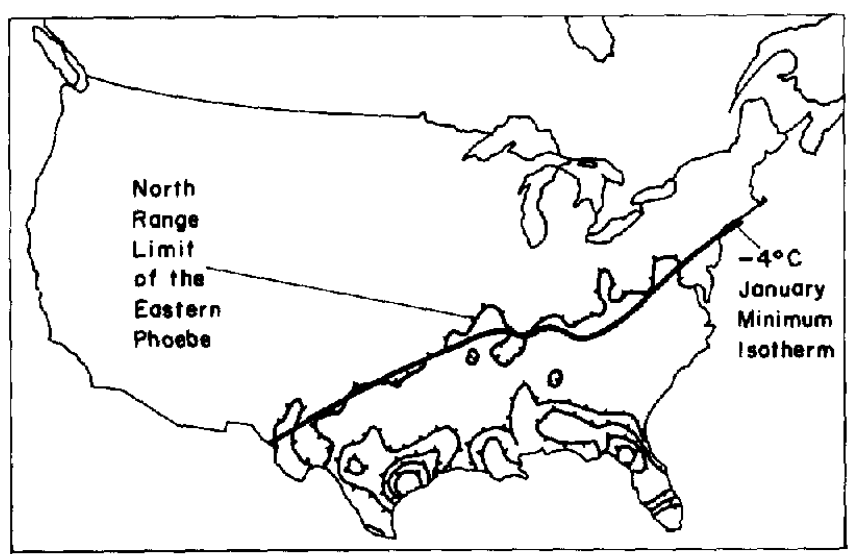

Figure 4. The distribution and abundance of the winter range of the Eastern Pboebe. The northern boundary lies very close to the $-4^{\circ} \mathrm{C}$ isotherm of January minimum temperature (beary solid line). Source: Root 1988a. quences of global warming on animals in general and birds in specific, the triangle linkages between animals, plants, and climate need to be understood. The triangle closes when the effects of altered surface vegetation, for example, are considered, because midcontinental summer precipitation is significantly influenced by evapotranspired water vapor.

One representative case, which has been described by Botkin and coworkers ( 1991 ), is that of the Kirtland's Warbler in northern Michigan. Its range is restricted to a narrow area of Jack Pine trees that grow in sandy soils in that region. Models of growth and decline of Jack Pine forests suggest that even a small climate change would be enough to devastate that habitat. The Jack Pines will move north, but the warbler will not be able to survive in the more northerly areas. This bird nests on the ground under relatively young pines. The soil to the north is not generally sandy enough to allow sufficient drainage for successful fledging of young (Cohn 1989). This scenario almost certainly dooms the warbler to extinction in $30-60$ years. This potential extinction is indicative of how the already high rate of extinctions around the world will be substantially exacerbated by climatic changes occurring more rapidly than species can adapt (see Wilson 1989; Peters \& Lovejoy 1992).

\section{Specific Example Using Wintering North American Birds}

Although climatic factors have long been thought to govern broad biogeographic patterns of animals (Andrewartha \& Birch 1954), rarely has this hypothesis been rigorously quantified (Brown \& Gibson 1983). To help redress this gap Root (1988a) undertook a massive study of the biogeographic patterns of all wintering North American birds. She found strong statistical correlations between the distribution and abundance of a majority of the 148 land bird and six large-scale environmental factors, which included average minimum January temperature, mean length of frost-free period, potential vegetation, mean annual precipitation, average humidity, and elevation (Root 1988a, 1988b, 1989). Figure 4 depicts the striking association between the average minimum January temperature and the northern range limit of the Eastern Phoebe. Associations were quantified by finding the area between the range boundary and an environmental isopleth (see Fig. 4) and then dividing by the length of the range boundary. Less than $1 \%$ of the possible associations between the species' ranges and environmental factors are expected to occur by chance. Certainly, other methods can be used to quantify the association between birds' northern boundaries and environmental isopleths, such as examining the range of temperatures spanned across a given 
boundary or the standard deviation of temperatures along the boundary (Repasky 1991). Such onedimensional heuristic measures may be easier to calculate than the two-dimensional average-area deviation method of Root (1988b), but they cannot provide the same level of detail and focus necessary for certain large-scale questions. The relevance of this for our discussion is that the methods used to associate temperature and range limits can lead to different inferences; therefore a method must be chosen that is the most appropriate to specific scientific questions, such as quantifying the extent of association between birds' northern boundaries and temperature, without introducing complicating extraneous factors such as packed isotherms or edge effects that would accompany the one-dimensional method.

Associations with species' southern boundaries in North America are ignored because a large majority of the species have range limits abutting the edge of the study area (Root 1988b). The comparisons along the northern, eastern, and western boundaries of species' ranges reveal that environmental factors show frequent associations (Fig. 5). Indeed, more than one factor often associates with a given range limit, which is expected because the factors are not independent. With such a large number of range boundaries of wintering birds associated with various climatic and vegetation variables (see Root $1988 a$ for details), changes in global climate could easily facilitate the reshaping and relocation of a significant number of these ranges.

\section{Possible Physiological Constraints Facilitating the Bird-Climate Linkage}

Physiological constraints quite possibly are driving the much-better-than-chance associations between average January minimum temperature and northern range limits for a number of species (Root 1988b). Of the 51 species of songbirds (passeriformes) found to have their northern range limits strongly associated with ambient temperature (Root 1988a), winter physiology studies

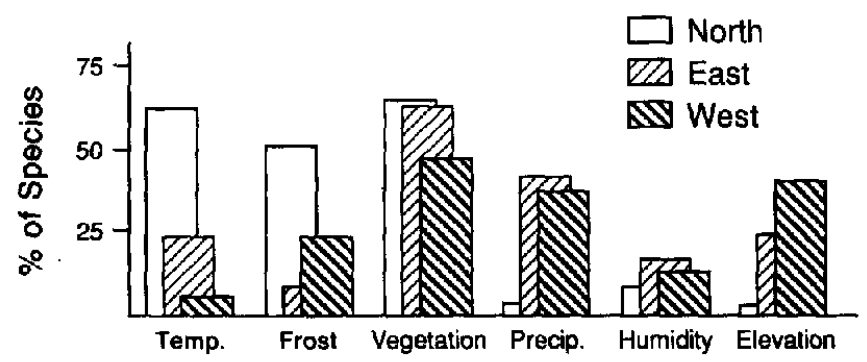

Figure 5. Plot of the percentage of species' nortbern, eastern, and western range boundaries associated with six environmental factors. See text for explanation of terms. After: Root 1988a. had been reported in the literature on 14. From these studies Root obtained lower critical temperature (TCRIT, the ambient temperature at which if it gets colder an individual must increase its metabolic rate to maintain thermal homostasis), the basal metabolic rate ( $B M R$, the metabolic rate of a night-resting individual at an ambient temperature a few degrees above its TCRIT), and conductance (COND, the heat loss of an individual as the ambient temperature drops below TCRTT).

Figure 6 depicts the relationship between the measured physiological values, temperature at the northern boundary of the distribution, and the value for the metabolic rate at the northern boundary of the distribution (NBMR). The equation used to derive NBMR is

$$
N B M R=\left[(T C R T T-T D I S T){ }^{*} C O N D\right]+B M R,
$$

with TDIST and TCRIT measured in degrees C, BMR and $N B M R$ in kilojoules per day, and COND in kilojoules per day per bird per degree $C$. For all the birds examined, Root found that their metabolic rate at their northern boundaries was statistically constant multiple of their basal rate. The relationship between these two metabolic rates is

$$
N B M R \simeq 2.5 B M R
$$

The ratio of $N B M R$ to $B M R$ shows little variation among species; the mean of this ratio is 2.49 , with a standard

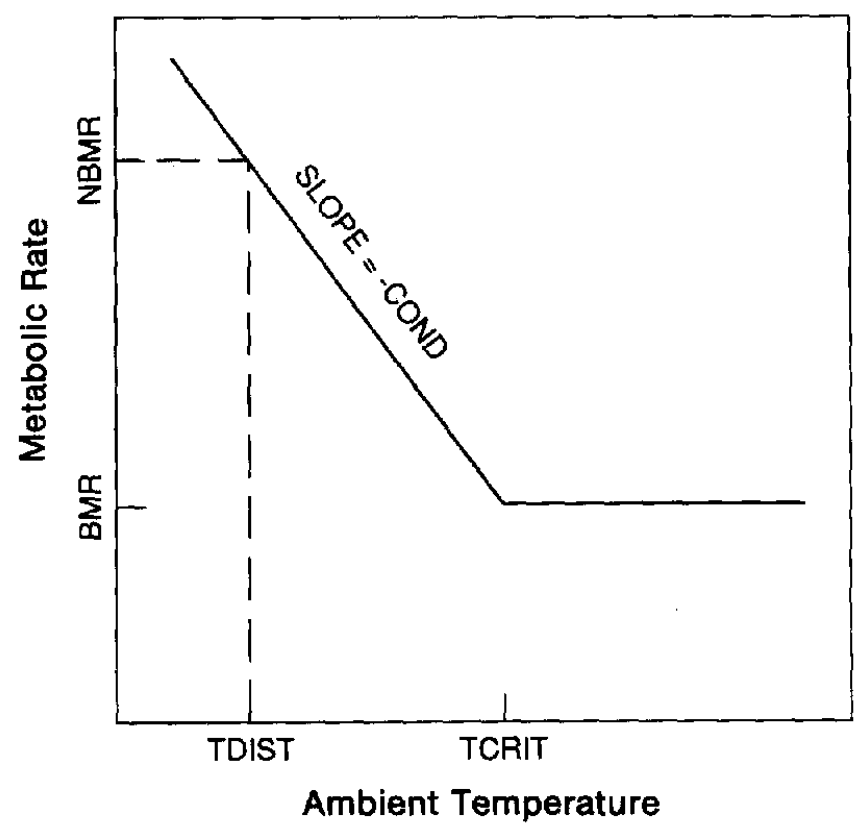

Figure 6. A scbematic representation of the relationship between metabolic rate and ambient temperature. $B M R=$ basal metabolic rate; $C O N D=$ conductance, $T C R I T=$ lower critical temperature; $N B M R=$ northern boundary metabolic rate; TDIST = average minimum January temperature at the northern distribution edge. Source: Root 1988b. 
error of \pm 0.07 . The $95 \%$ confidence limit around the regression line defining the $N B M R$ and $B M R$ relationship provides values that range from 1.95 to 2.93 (Root 1989).

Basal metabolic rate is strongly related to body mass (Aschoff \& Pohl 1970; Root 1988b). Consequently, the relationship stated in Equation 2 suggests, as Repasky (1991) correctly points out, that large species should occur farther north than smaller species. This is exactly what is found for species whose northern range boundary associated with temperature isotherms (Root \& Price, in preparation). Small-bodied birds that do not have their northern range boundary limited by temperature do, of course, occur in the north. These appear to be exceptions (Repasky 1991), but they actually help prove the rule, because they all have adopted energysaving mechanisms that allow them to extend their ranges farther north than expected from Equation 2. For instance, some of the more northerly small-bodied birds have developed physiological mechanisms, such as hypothermia in the Black-Capped Chickadee (Reinertsen 1983), or behavioral mechanisms, such as roosting in cavities as in the Brown Creeper (Ehrlich et al. 1988).

The calculated metabolic rates at edges of species' distributions (Root 1988b) are based on resting metabolic rates, and they do not account for extra heat generated-for example, during digestion or activity. One of the assumptions of these calculations is that ambient temperature is an adequate index of an individual's thermal environment. Certainly, microhabitats and wind conditions have great influence on the energy expended to keep warm (Buttemer 1985). Nevertheless, average minimum January temperature appears to describe, to the first order, the wide-scale thermal environment of many species; but certainly more study is needed. Further investigations will help determine if a connection exists between the seemingly ubiquitous value of about 2.5 BMR for the nightime metabolic rate at the northern edge of winter distributions and the daily energy expenditures expounded by other workers (see Drent \& Daan 1980; Walsburg 1980; Peterson et al. 1990), or if the similar values are just an unusual coincidence.

This type of analysis implies that, as climate changes, the physiological tolerance of some birds could cause them-habitat permitting - to change their ranges as rapidly as the climate changes. The range changes in those species for which the habitat is not permitting will probably not be as extreme or as rapid, and those species with ranges not associated with ambient temperature will probably not exhibit an immediate change in range-unless some limiting factor or competitor is sensitive to climate. Such differential movements of species will certainly cause a tearing apart of communities, thereby forcing potentially dramatic restructurings and reorganizations. The important point we wish to reiter- ate is that analyses at large scales (so-called "top-down" studies) can indicate which smaller-scale studies (at the "bottom-up" community level or of single species) are most likely to help assess the ecological implications of global changes and to help design conservation measures in response.

\section{Forecasting Potential Changes in Species Communities: Integrating Field and Large-Scale Studies}

Three major research activities are needed before we will be able to forecast reliably the potential effects that global climatic change will have on species' communities throughout North America. First, much can be learned about the effects of global warming by studying prehistoric species communities that underwent a warming event of similar magnitude from the glacial to the interglacial period. However, important differences between prehistoric and forecasted climate changes, such as the presence of glaciers and the sustained average rate of temperature change being an order of magnitude slower in ancient times, certainly prevent direct comparisons. Consequently, generalities rather than specifics will be the most helpful. For instance, Graham and Mead (1987) note that environmental changes associated with the last deglaciation (so called "Termination 1" in the marine record) had profound effects on the restructuring of biotic communities in North America. Vertebrate species, especially mammals, are particularly useful proxies for these changes, so they provide excellent documentation of the climatic fluctuations of the late Quaternary.

In general, mammals responded to the last deglaciation in North America by shifting their ranges relatively quickly (Graham \& Mead 1987). Graham and Grimm (1990), however, caution against extensive reliance on past conditions in forecasting future patterns. They argue that predicting community response to greenhouse warming becomes particularly hazardous as the typically forecasted temperature increase exceeds that of any period of the last 120,000 years, a conclusion reflecting the results of Davis's (1990) study concerning forest-species response. Future climates may lie not only outside the existing climatic domain, but also outside our paleoclimatic database and outside the climate to which existing species are evolutionarily adapted. Therefore, changes inferred from past changes can be taken only as a heuristic guide to possible future changes. If past changes are used to calibrate and validate models of climate-mammal interactions, however, then such models may provide more credible projections of the effects of climatic change on mammalian distributions and abundances (Schneider 1992b). 
Second, more research is obviously needed on the ecology, behavior, and physiology of individual species, but it needs to be designed and coordinated with larger-scale studies to increase our understanding of bow biogeograpbic patterns may change as the climate changes. Certainly, large-scale studies need to be encouraged, as they currently constitute only a small fraction of ecological research efforts. Such studies can be used to indicate the types of small-scale studies needed. For example, large-scale studies can indicate which species have patterns that suggest their ranges may be lim. ited by temperature. In-depth studies on the species' ecology, behavior, physiology, and the like, are then needed to understand possible mechanisms acting to shape the broader patterns. Community studies are also needed to investigate how species' interactions might be influenced by changes in climate. Species compositions of communities may be forced into flux, and, as a result, significant climatic fluctuations will cause major biotic reorganizations.

To fully understand the effects of global warming on species' communities, biogeographical, ecological, behavioral, and physiological studies need to be done not only on birds, but on all organisms occurring within various communities. For example, the prey base of birds in a community may be strongly affected by changing climate. Indeed, Coope (1977) has shown a high sensitivity of both individual species and assemblages of beetles to climatic change. More in-depth studies are needed not only on invertebrates but also on vertebrate members of various communities.

Third, the scientific community needs to foster interdisciplinary work or, at a bare minimum, multidisciplinary work, that will combine information from a broad spectrum of research: climatology, hydrology, limnology, soil science, chemistry, entomology, mammalogy, ornithology, botany, and so on. By integrating relevant information from all these fields, a more comprehensive model can be built that should forecast more reliably the spectrum of consequences that continued release of greenhouse-effect gases will have on ecosystems. This will require actively opening communications among scientists in different fields. This can be a time-consuming activity, not only because the jargon varies significantly among fields but also because groups within the scientific community are structured primarily around disciplines rather than around problems (see Chen 1981; Schneider 1988; Bella \& King 1989).

Also, the reward system within the scientific community is typically such that interdisciplinary work is not valued as highly as disciplinary work (in other words, single-authored papers count more toward promotion than multi-authored ones, and granting agencies are set up to fund disciplinary work more easily than interdisciplinary work). Such barriers are common at the cut- ting edge of problem solving, but they must be breached before the complex problems caused by global climatic change can be adequately addressed (see Schneider 1992b).

\section{Outreach}

The possible biological consequences of global warming range from mild to catastrophic. The best guess of knowledgeable scientists is that there is a $60 \%$ chance that the world will warm 1.5 to $4.5^{\circ} \mathrm{C}$ in the next century (IPCC 1990, as explained by Schneider 1993a, from which part of earlier sections were modified). On the one hand, some people may say that the odds of significant damage are too low or that uncertainty is too high to act now. The problem with this argument is that the concern should be not only over the value of the probability but also about the potential magnitude of the consequences of global warming. A good analogy is that of a person having a $60 \%$ chance of getting a cold if a certain activity is performed: the cost of that action-a cold-is often low enough that a probability as "low" as $60 \%$ does not modify the person's behavior. If the cost of a given activity is contracting a fatal disease, however, then a $60 \%$ probability-even a $6 \%$ chancewould be of major concern, and dramatic steps would be taken to avoid the activity. This is the principle behind insurance investments or risk-averse deterrence expenditures (see Schwing \& Albers 1980).

The scientific community has the ability to determine a range of probable consequences of global warming. As these consequences-whether they are mild or catastrophic-become as clearly identified and understood as possible, policy makers will be able to use this information to structure the type of actions that are needed. Without providing an outreach to policy makers and the general public, we as a scientific community abdicate our responsibility of providing or interpreting scientific information to people who often have specific agendas or selfish interests. Hence, the scientific community as a whole needs to acknowledge the importance of providing, in clear language, research results needed by decision makers and to participate in the dissemination of our information. Finally, there must be incentives to encourage those in the scientific community to competently fill this role.

\section{Implications for Policy}

Climatic change is not necessarily a threat to the viability of all climate-sensitive species. However, the tran. sient nature of most projected human-induced climatic change is on a scale of decades, while the adaptability of many species-or species upon which faster-responding 
species depend-is on a scale of centuries. This implies that substantial disequilibrium within ecosystems could be created owing to maladaptions, significant shifts in species ranges, and inevitable extinctions. Consequently, the only outcome that can be predicted with virtual certainty is major surprises. The only forecast that seems certain is that the more rapidly the climate changes the bigher the probability of substantial disruption and surprise within natural systems. Dramatic disruption of communities can be expected to occur in the next century. To be able to forecast possible consequences of the projected warming, single-species studies need to be guided by the overall effects that climate may have on the large-scale biogeographic patterns and on the ecology, behavior, and physiology of all species (see Root 1988a, 1988b). Coupling results together with information from climatologists, geologists, and others, models that will allow us to forecast more reliably the possible biological consequences of scenarios of global warming need to be designed and validated. These forecasts can then be used by policy makers and the general public to determine what types of actions are needed to impede the rapid increase in the global temperature or to ameliorate its impact on natural systems.

These possibilities have led to a debate as to whether humans need to intervene as "ecological engineers," deliberately removing soon-to-be maladapted species and holding them in captive breeding programs for reintroductions later, or translocating wild individuals into potentially more hospitable environments (Roberts 1988; Soulé 1989; Peters \& Lovejoy 1992). Rapid global warming will certainly increase the number of species that are maladapted to their climatically-changed habitats. This rapid change, the effects of which may need to be artificially mediated by humans, is created by the increasing use of energy and materials demanded by growing populations insisting on using the cheapest and most readily available technologies to increase their standards of living (see Ehrlich \& Holdren 1971).

The most politically acceptable strategy is to accelerate the implementation of already cost-effective activities that also slow down the emissions of greenhouse gases into the atmosphere. Such activities, which have been called the "tie-in" principle, include more efficient production and uses of fossil fuels, curtailing the production and use of CFCs, and more effective use of nitrogen fertilizer. Although deciding how to act always involves value judgments, we believe humans must invest more present resources as a hedge against potential change. Those actions that are already cost effective (using and producing energy more efficiently is the most important example), should be vigorously pursued now, political obstacles slowing the penetration of existing cost-effective actions should be removed, and incentives to speed such action should be created (see $\mathrm{Na}$ - tional Academy of Sciences 1991; Office of Technology Assessment 1991).

Even though IPCC (1990) has shown that it would take a dramatic $60 \%$ or so reduction in $\mathrm{CO}_{2}$ emissions to stabilize $\mathrm{CO}_{2}$ concentrations in the atmosphere in the decades ahead, less dramatic emissions reductions would reduce the rate at which climatic changes would proceed. And, as it has been argued here and elsewhere, it is likely the rate of change of climate that most tbreatens ecosystem disruptions. Therefore, we believe that slowing down the rate of global change is a priority for the world's environment/development policy agenda.

These high-leverage or tie-in strategies (see Schneider 1990) are long overdue for a higher place on the world's agenda-with or without global warming. Because of the urgency of the need to slow down global climate change, and thereby to buy time for humans to assess and the rest of nature to adapt to whatever changes will take place, accelerating the implementation of such actions seem self-evidently the most appropriate immediate policy response to the prospect of unprecedentedly rapid climatic changes.

\section{Acknowledgments}

We would like to thank Philippe Martin and Simon Levin and reviewers Charles Hall and J.S. Turner for helpful criticism of earlier drafts of this paper. This work was partially funded by grants from the Winslow Foundation, the U.S. Fish and Wildlife Service Cooperative Research Center, and the National Science Foundation (BSR-9058031).

\section{Literature Cited}

Aschoff, J., and H. Pohl. 1970. Rhythmic variations in energy metabolism. Federation Proceedings 29:1541-1552.

Andrewartha, H. G., and L. C. Birch. 1954. The distribution and abundance of animals. University of Chicago Press, Chicago, Illinois.

Arnold G. W. 1988. Possible effects of climatic change on wildlife in Western Australia. Pages 375-386 in G. I. Pearman, editor. Greenhouse: Planning for climate change. Brill Publishing Company, Leiden, The Netherlands.

Barron J., and A. D. Hecht, editors. 1985. Historical and paleoclimatic analysis and modeling. John Wiley and Sons, New York, New York

Bella, D., and J. King. 1989. Common knowledge of the second kind. Journal of Business Ethics 8:415 -430 .

Berger, A., J. Imbrie, J. Hays, G. Kukla, and B. Saltzman, editors. 1984. Milankovitch and climate. Parts 1 and 2. D. Reidel Publishing Company, Dordrecht, The Netherlands. 
Bonan, G. B., H. H. Shugart, and D. L. Urban. 1990. The sensitivity of some high-latitude boreal forests to climatic parameters. Climatic Change 16:9-29.

Botkin, D. B., J. R. Janak, and J. R. Wallis. 1972. Rationale, limitations and assumptions of a northeast forest growth simulator. IBM Journal of Research and Development 16:101-116.

Botkin, D. P., and R. A. Nisbet. 1992. Forest response to climatic change: Effects of parameter estimation and choice of weather patterns on the reliability of projections. Climatic Change, 20:87-112.

Botkin, D. P., D. A. Woodby, and R. A. Nisbet. 1991. Kirtland's Warbler habitat: A possible early indicator of climate warming. Biological Conservation 56(1):63-78.

Brown, J. H., and A. C. Gibson. 1983. Biogeography. Mosby, St. Louis, Missouri.

Brown, J. H., and B. A. Maurer. 1989. Macroecology: The division of food and space among species on continents. Science 243:1145-1150.

Budyko, M. I., A. B. Ronov, and A. L. Yanshin. 1987. History of the earth's atmosphere. Springer-Verlag, New York, New York.

Buttemer, W.A. 1985. Energy relations of winter roost-site utilization by American Goldfinches (Carduelis tritis). Oecologia (Berlin) 68:126-132.

Chen, R.S. 1981. Interdisciplinary research and integration: The case of $\mathrm{CO}_{2}$ and climate. Climatic Change 3:429-447.

COHMAP Members. 1988. Climatic changes of the last 18,000 years: Observations and model simulations. Science 241:1043.

Cohn, J. P. 1989. Gauging the biological impacts of the greenhouse effect. BioScience 39:142-146.

Coope, G. R. 1977. Fossil coleopteran assemblages as sensitive indicators of climate changes during the Devensian (Last) cold stage. Proceedings of the Philosophical Transactions of the Royal Society of London B(280):313-340.

Crowley, T. 1993. Use and misuse of the geologic "analogs" concept. In Global changes in the perspective of the past. Dahlem Workshop Report ES12. Chichester: John Wiley \& Sons. In press.

Davis, M. B. 1990. Climatic change and the survival of forest species. Pages 99-110 in G. M. Woodwell, editor. The earth in transition: Patterns and processes of biotic impoverishment. Cambridge University Press, Cambridge, England.

Davis, M. B., and C. Zabinski. 1992. Changes in geographical ranges resulting from greenhouse warming effects on biodiversity in forests. Pages 297-308 in R. Peters and T. Lovejoy, editors. Global warming and biological diversity. Yale University Press, New Haven, Connecticut.

Dickinson, R. E., R. M. Errico, F. Giorgi, and G. T. Bates. 1989. A regional climate model for the western United States. Climatic Change 15:383-422.
Doyle, T. W. 1981. The role of disturbance in the gap dynamics of a montane rain forest: An application of a tropical forest succession model. Pages $56-73$ in D. C. West, H. H. Shugart, and D. B. Botkin, editors. Forest succession: Concepts and applications. Springer-Verlag, New York, New York.

Drent, R. H., and S. Daan. 1980. The prudent parent: Energetic adjustments in avian breeding. Ardea 68:62-63.

Ehrlich, P. R, and J. P. Holdren. 1971. Impact of population. Science 171:1212-1217.

Ehrlich, P. R., D. S. Dobkin, and D. Wheye. 1988. The birder's handbook. Simon and Schuster, New York, New York.

Emanuel, K A. 1987. The dependence of hurricane intensity on climate. Nature 326:483-485.

Gates, D. M. 1980. Biophysical ecology. Springer-Verlag, New York, New York.

Gates, W. L. 1985. The use of general circulation models in the analysis of the ecosystem impacts of climatic change. Climatic Change 7:267-284.

Giorgi, F. 1990. Simulation of regional climate using a limited area model nested in a general circulation model. Journal of Climate 3:941-963.

Graetz, R. D., B. H. Walker, and P. A. Walker. 1988. The consequences of climatic change for seventy percent of Australia. Pages $399-420$ in G. I. Pearman, editor. Greenhouse: Planning for climate change. Brill Publishing Company, Leiden, The Netherlands.

Graham, R. W., and E. C. Grimm, 1990. Effects of global climate change on the patterns of terrestrial biological communities. Trends in Ecology and Evolution 5:289-292.

Graham, R. W., and J. I. Mead. 1987. Environmental fluctuations and evolution of mammalian faunas during the last deglaciation in North America. Pages 371-402 in W. F. Ruddiman and H.E. Wright, editors. North America and adjacent oceans during the last deglaciation. Geological Society of America, Boulder, Colorado, vol. K-3.

Intergovernmental Panel on Climate Change. 1990. J. T. Houghton, G. J. Jenkins, and J.J. Ephraums, editors. Climate Change: The IPCC Scientific Assessment. Cambridge University Press, Cambridge, England.

Intergovernmental Panel on Climate Change. 1992. J. T. Houghton, G.J. Jenkins and J.J. Ephraums, editors. Climate Change 1992: The Supplementary Report to the IPCC Scientific Assessment. Cambridge University Press, Cambridge, England.

Jackson, J. A. 1974. Gray rat snakes versus Red-Cockaded Woodpeckers: Predator-prey adaptations. Auk 91:342-347.

Jager, J., and W.W. Kellogg. 1983. Anomalies in temperature and rainfall during warm arctic seasons. Climatic Change $5: 39-60$.

Jager, J. 1988. Developing policies for responding to climatic change: A summary of the discussions and recommendations 
of the workshops held in Villach (WCIP-1, WMO/TD-No. 225) September 28 to October 2, 1987. World Metoeorological Organization, Geneva, Switzerland.

James, D. 1962. The changing seasons. Audubon Field Notes 16:306-311.

Kareiva, P., and M. Andersen. 1988. Spatial aspects of species interactions. Pages $35-50$ in A. Hastings, editor. Community ecology: Workshop held at Davis, California, April 1986. Springer-Verlag, New York, New York.

Levin, S. A. 1992. The problem of pattern and scale in ecology. Ecology 73:1943-1967.

Lough, J. M., T. M. L. Wigley, and J. P. Palutikof. 1983. Climate and climate impact scenarios for Europe in a warmer world. Journal of Climate and Applied Meteorology 22:1673.

Lynch, M., and R. Lande. 1993. Evolution and extinction in response to environmental change. Pages 234-250 in J. Kingsolver, P. Kareiva, and R. Huey, editors. Biotic interactions and global change. Sinauer Associates, Sunderland, Massachusetts.

Main, A. R. 1988. Climatic change and its impact on nature conservation in Australia. Pages 361-374 in G. I. Pearman, editor. Greenhouse: Planning for climate change. Brill Publishing Company, Leiden, The Netherlands.

Martin, P. 1990 . Forest succession and climatic change: Coupling land-surface processes and ecological dynamics. Thesis no. 131. National Center for Atmospheric Research, Boulder, Colorado.

McDonald, K. A., and J. H. Brown, 1992. Using montane mammals to model extinctions due to global change. Conservation Biology 6:409-415.

Mearns, L. O., R. W. Katz, and S. H. Schneider. 1984. Extreme high temperature events: Changes in their probabilities and changes in mean temperature. Journal of Climate and Applied Meteorology 23:1601-1613.

Mearns, L. O., P. Gleick, and S. H. Schneider. 1990a Climate forecasting. Pages 87-137 in P. E. Waggoner, editor. Climate change and U.S. Water Resources. John Wiley and Sons, New York, New York.

Mearns, L. O., S. H. Schneider, S. L. Thompson, and L. McDaniel. $1990 \mathrm{~b}$. Analysis of climate variability in general circulation models: Compared with observations and changes in variability in $2 \mathrm{xCO}_{2}$ experiments. Geophysical Research 95:20,46920,490 .

Mengel, R. M., and J. A. Jackson. 1977. Geographic variation of the Red-Cockaded Woodpecker. Condor 79:349-355.

National Academy of Sciences. 1987. Current issues in atmospheric change. National Academy Press, Washington, D.C.

National Academy of Sciences. 1991. Policy implications of greenhouse warming. National Academy Press, Washington, D.C.

O'Brien, S. T., B. P. Hayden, and H. H. Shugart. 1992. Global climate change, hurricanes, and a tropical rain forest. Climatic Change 22:175-190.
Office Of Technology Assessment. 1991. Changing by degrees: Steps to reduce greenhouse gases. U.S. Government Printing Office, Washington, D.C.

Parry, M. L, and T. R. Carter, 1985. The effect of climatic variations on agricultural risk. Climatic Change 7:95-110.

Pastor, J., and W. M. Post. 1988. Response of northern forest to $\mathrm{CO}_{2}$-induced climate change. Nature 334:55-58.

Peters, R., and T. Lovejoy, editors. 1992. Global warming and biological diversity. Yale University Press, New Haven, Connecticut.

Peterson, C. C., K. A. Nazy, and J. Diamond. 1990. Sustained metabolic scope. Proceedings of the National Academy of Sciences 87:2324-2328.

Pittock, A. B., and J. Salinger. 1982. Towards regional scenarios for a $\mathrm{CO}_{2}$-warmed earth. Climatic Change 4:23-40.

Reinertsen, K.W. 1983. Nocturnal hypothermia and its energetic significance for small birds living in the arctic and subarctic regions: A review. Polar Research 1:269-284.

Repasky, R. R. 1991. Temperature and the northern distributions of wintering birds. Ecology 72:2274-2285.

Rind, D., R. Goldberg, and R. Ruedy. 1989. Change in climate variability in the 21 st century. Climatic Change 14:5-37.

Roberts, L. 1988. Is there life after climate change? Science 242:1010-1012.

Root, T. L. 1988 anvironmental factors associated with avian distributional boundaries. Journal of Biogeography 15:489. 505.

Root, T. L. 1988b. Energy constraints on avian distributions and abundances. Ecology 69:330-339.

Root, T. L. 1988c Atlas of wintering North American birds. University of Chicago Press, Chicago, Illinois.

Root, T. I. 1989. Energy constraints on avian distributions: A reply to Castro. Ecology 70:1183-1185.

Root T. L. 1992. Effects of global climate change on North American birds and their communities. Pages 280-292 in J. Kingsolver, P. Kareiva, and R. Huey, editors. Biotic interactions and global change. Sinauer Associates, Sunderland, Massachusetts.

Schlesinger, M. E., and J. Mitchell, 1987. Climate model simulations of the equilibrium climatic response to increased carbon dioxide. Review of Geophysics 25:760-798.

Schneider, S. H. 1984. On the empirical verification of modelpredicted $\mathrm{CO}_{2}$-induced climatic effects. Pages 187-201 in J. Hansen and T. Takahashi, editors. Climate processes and climate sensitivity. American Geophysical Union, Washington, D.C.

Schneider, S. H. 1987. Climate modeling. Scientific American 256(5): 72-80. 
Schneider, S. H. 1988. The whole earth dialogue. Issues in science and technology IV(3):93-99.

Schneider, S. H. 1990. Global warming: Are we entering the greenhouse century? Vintage Books, New York, New York.

Schneider, S. H. 1991. Three reports of the Intergovernmental Panel on Climate Change. Environment 33:25-30.

Schneider, S.H. 1992a Will sea levels rise or fall? Nature 356:11-12.

Schneider, S. H. 1992b. The role of the university in interdisciplinary global change research: Structural constraints and the potential for change. An editorial. Climatic Change 20(1):vii-x.

Schneider, S.H. 1993a Scenarios of global warming. Pages 9-23 in J. Kingsolver, P. Kareiva, and R. Huey, editors. Biotic Interactions and Global Change. Sinauer Associates, Sunderland, Massachusetts.

Schneider, S. H. 1993b. Can paleoclimatic and paleoecological analyses validate future global climate and ecological change projections? In Global changes in the perspective of the past. Dahlem Workshop Report ES12. Chichester: John Wiley \& Sons. In press.

Schneider, S. H., and S. L. Thompson. 1981. Atmospheric $\mathrm{CO}_{2}$ and climate: Importance of the transient response. Journal of Geophysical Research 86:3135-3147.

Schwing R. C., and W.A. Albers, editors. 1980. Societal risk assessment: How safe is safe enough? Plenum Press, New York, New York.

Soulé, M. 1989. Conservation biology in the 21st century. Pages 297-303 in D. Western and M. Pearl, editors. Conservation for the 21 st century. Oxford University Press, New York, New York.

Stouffer, R. J., S. Manabe, and K. Bryan. 1989. Interhemispheric asymmetry in climate response to a gradual increase of atmospheric $\mathrm{CO}_{2}$. Nature, 342:660-662.

Strain, B. R. 1987. Direct effects of increasing atmospheric $\mathrm{CO}_{2}$ on plants and ecosystems. Trends in Research in Ecology and Evolution 2:18-21.
Terborgh, J. 1971. Distribution on environmental gradients: Theory and a preliminary interpretation of distributional patterns in the avifauna of the Cordillera Vilcabamba, Peru. Ecology 52:23-40.

Thompson, S. L., and S. H. Schneider. $1982 . \mathrm{CO}_{2}$ and climate: the importance of realistic geography in estimating the transient response. Science 217:1031-1033.

Torn, M.S., and S.J. Fried. 1992. Predicting the impacts of global warming on wildland fire. Climatic Change. In press.

Walsberg, G. E. 1980. Energy expenditure in free-living birds: Patterns and diversity. Proceedings of the International Ornithological Congress, XVII:300-305.

Washington, W. M., and G. H. Meehl. 1989. Climate sensitivity due to increased $\mathrm{CO}_{2}$ : Experiments with a coupled atmosphere and ocean general circulation model. Climate Dynamics 4:1-38.

Watt, W. B. 1992. Eggs, enzymes and evolution-natural genetic variants change insect fecundity. Proceedings of the National Academy of Sciences. National Academy Press 89:10608-10612.

Whittaker, R.H. 1970. Communities and ecosystems. MacMillan, New York, New York.

Wigley, T. M. L. 1985. Impact of extreme events. Nature 316:106-107.

Wigley, T. M. L., and S. C. B. Raper. 1991. Detection of the enhanced greenhouse effect on climate. Pages 231-242 in J. Jager and H. L. Ferguson, editors. Climate change: Science, impacts and policy. Cambridge University Press, Cambridge, England.

Wilcove, D. S., C. H. McLellan, and A. P. Dobson. 1986. Habitat fragmentation in the temperate zone. Pages 237-256 in $\mathrm{M}$. Soule, editor. Conservation biology: The science of scarcity and diversity. Sinauer Associates, Sunderland, Massachusetts.

Wilson, E. O. 1989. Threats to biodiversity. Scientific American 261: 108-116.

Woodward, F. I. 1987. Climate and plant distribution. Cambridge University Press, Cambridge, England. 